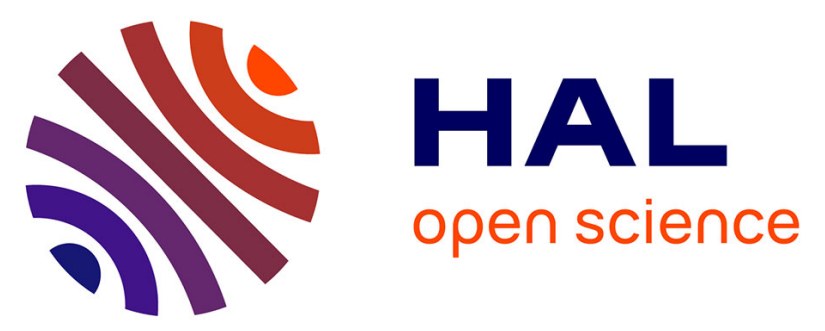

\title{
Fire tests carried out in FCH JU FIRECOMP project, recommendations and application to safety of gas storage systems
}

Pierre Blanc-Vannet, Simon Jallais, B. Fuster, Fabien Fouillen, Damien Halm, Tom van Eekelen, S. Welch, P. Breuer, Stuart Hawksworth

\section{To cite this version:}

Pierre Blanc-Vannet, Simon Jallais, B. Fuster, Fabien Fouillen, Damien Halm, et al.. Fire tests carried out in FCH JU FIRECOMP project, recommendations and application to safety of gas storage systems. 7. International conference on hydrogen safety (ICHS 2017), Sep 2017, Hambourg, Germany. pp.496508. ineris-01863242

HAL Id: ineris-01863242

https://hal-ineris.archives-ouvertes.fr/ineris-01863242

Submitted on 28 Aug 2018

HAL is a multi-disciplinary open access archive for the deposit and dissemination of scientific research documents, whether they are published or not. The documents may come from teaching and research institutions in France or abroad, or from public or private research centers.
L'archive ouverte pluridisciplinaire HAL, est destinée au dépôt et à la diffusion de documents scientifiques de niveau recherche, publiés ou non, émanant des établissements d'enseignement et de recherche français ou étrangers, des laboratoires publics ou privés. 


\title{
FIRE TESTS CARRIED OUT IN FCH JU FIRECOMP PROJECT, RECOMMENDATIONS AND APPLICATION TO SAFETY OF GAS STORAGE SYSTEMS
}

\author{
P. Blanc-Vannet ${ }^{1 *}$, S.Jallais ${ }^{1}$, B.Fuster ${ }^{1}$, F.Fouillen ${ }^{2}$, D.Halm ${ }^{3}$, T.van Eekelen ${ }^{4}$, S. Welch ${ }^{5}$, \\ P.Breuer $^{6}$, S.Hawksworth ${ }^{7}$ \\ ${ }^{1}$ Air Liquide Research and Development, 1 Chemin de la porte des loges, BP 126 - 78354 Jouy \\ en Josas, France, pierre.blanc-vannet@airliquide.com \\ ${ }^{2}$ INERIS, Rue Jacques Taffanel, 60550 Verneuil-en-Halatte \\ ${ }^{3}$ Institut Pprime, CNRS - ENSMA - Université de Poitiers, Chasseneuil, France \\ ${ }^{4}$ Samtech SA - a Siemens company, Liège, Belgium \\ ${ }^{5}$ School of Engineering, The University of Edinburgh, Edinburgh, EH9 3JL, UK \\ ${ }^{6}$ Hexagon Composites, Raufoss, Norway \\ ${ }^{7}$ Health and Safety Laboratory, Buxton, Derbyshire, UK
}

\begin{abstract}
In the event of a fire, composite pressure vessels behave very differently from metallic ones: the material is degraded, potentially leading to a burst without significant pressure increase. Hence, such objects are, when necessary, protected from fire by using thermally-activated devices (TPRD), and standards require testing cylinder and TPRD together. The pre-normative research project FireComp aimed at understanding better the conditions which may lead to burst, through testing and simulation, and proposed an alternative way of assessing the fire performance of composite cylinders. This approach is currently used by Air Liquide for the safety of composite bundles carrying large amounts of hydrogen gas.
\end{abstract}

\section{NOMENCLATURE}

TPRD Thermally activated Pressure Relief Device

$E_{g} \quad$ Thermal energy stored by the gas

$T_{g} \quad$ Temperature of the gas

$m_{g} \quad$ Mass of gas

$m_{c y l} \quad$ Mass of the cylinder

$C_{p_{g}} \quad$ Specific heat capacity

$C_{p_{\text {steel }}}$ Specific heat capacity of the steel

$S_{i} / S_{e}$ Internal / External wall surface

$\phi_{S_{i} \rightarrow g}$ Heat flux transmitted by the internal wall surface

$\phi_{c y l} \quad$ Net heat flux absorbed by the vessel

$T_{S_{i}} \quad$ Average temperature of the internal wall of the cylinder

$h \quad$ Areal transfer coefficient between gas and inner wall

$\phi \quad$ Heat flux absorbed by the cylinder

$\lambda$ Thermal conductivity

e Thickness

\subsection{INTRODUCTION}

Type IV pressure vessels, typically made of a carbon fibre-epoxy composite shell wrapped around a polymeric liner, are considered a mature way of storing hydrogen at high pressure. Their use is increasing for applications requiring lightness and/or high pressure, such as on-board storage for cars or large vessels mounted on trailers. Though they can already be operated safely, a number of material issues and $\mathrm{R} \& \mathrm{D}$ challenges still limit their optimisation potential, including fire behaviour [1]. 
When exposed to fire, composite pressure vessels exhibit a completely different behaviour than metallic ones. For the latter, the heat is rapidly transferred to the gas, leading to a pressure increase, and ultimately cylinder burst when the pressure gets too high. On the other hand, the pressure in composite vessels tends not increase much more than about 10\%, whereas vessels are designed with safety factors of 2.25 to 3 . The degradation of the composite material can lead directly to a burst, or the melting of the plastic liner can lead to a leakage through the vessel's body. Whichever happens first depends on fire conditions, materials properties and tank geometry $[1,2]$. Due to the high energy content, the burst must be avoided, and the cylinders are protected with thermally activated pressure relief devices (TPRD), which must be placed in a way that ensures they detect the fire and vent the gas as required [3].

In current standards addressing the qualification of composite cylinders, either for on-board storage [4] or for transportable applications [5], it is required to test the vessel and its TPRD together in a bonfire test. The test is deemed a success if the gas vents through the TPRD and no burst occurs. For transportable applications in Europe, the use of TPRD is not mandatory: in that case, the cylinder must not burst before 2 minutes. A disadvantage of this method is that it does not provide much information on what the vessel alone can endure.

The European project FireComp [6, 7], a three-year FCH JU funded pre-normative research project which ended in June 2016, aimed at providing a better understanding of the failure of unprotected composite pressure vessels in fire. It brought together partners with different expertise: a hydrogen supplier as coordinator (Air Liquide), a composite vessels manufacturer (Hexagon), experts of industrial risks and safety (INERIS and HSL), experts in thermal radiation and mechanical behaviour of composites (CNRS, Samtech), in thermal degradation and reaction-to-fire (University of Edinburgh) and in collaborative research projects management (Ayming). Within the project an extensive bonfire test campaign was performed on 19L and 36L cylinders. Models were developed for heat transfer through the composite thickness [8] and loss of material strength with temperature [9, 10]. Used on real cylinder geometry, they proved able to accurately reproduce the experimental results and capture the transition between leak and burst failure modes [11].

This paper presents the fire test setup that was used, how the thermal aggression was calibrated using a metallic tube, the experimental results obtained, and how this knowledge is used for the fire protection of composite trailers.

\subsection{BONFIRE TESTS SETUP AND CALIBRATION}

The risk analysis underlined three possible types of fire: "punctual" jet fire (e.g. from an ignited hydrogen jet from piping), localised fire exposing a part of the cylinder (e.g. 30 to $50 \%$ of the surface), and fully engulfing fires [3]. Jet fires are known to lead to very quick burst of composite vessels [12] and are hardly detected by TPRDs; so the project focused on the two other types. Fully engulfing bonfire tests were retained, to create a conservatively severe thermal aggression.

Such fire tests were carried out by INERIS. The experimental programme comprised two steps. The first aimed at determining the fire conditions to test the thermo-mechanical behaviour of composite vessels in real conditions: metallic cylinders were instrumented in order to determine the incident equivalent heat flux, to calibrate the setup, and to record experimental data to be compared to the modelling results.

The second part of the study was performed on real composite vessels, using the thermal aggression determined in the first step. The results presented were obtained on type IV composite cylinders of $19 \mathrm{~L}$ and $36 \mathrm{~L}$. They were manufactured by Hexagon, by filament winding [13] around a polymeric liner and comprise one metallic boss at each end. The boss allows connecting the tank to the piping; the liner ensures the tightness of the vessel; and the role of the composite shell is to withstand the inner pressure. The service pressure is 700 bar. During manufacturing, thermocouples have been inserted in the composite wall, at different depths and locations. It was shown that they decrease a 
little the resistance of the composite (time to burst of one cylinder equipped with thermocouples was found to be $22 \%$ shorter than for one cylinder without), which is conservative for the approach considered below. These thermocouples were used to check the reproducibility of the fire and to provide data to compare with numerical simulations.

\subsection{Hydrogen gas burner and instrumentation}

Bonfire tests are typically performed using a hydrocarbon pool, where the quantity of liquid is regulated to ensure a constant flame regime $[2,14]$. The drawbacks of this type of test are that a large quantity of heptane mist is generated, which may lead to secondary explosion after cylinder burst and the necessity to extract fumes to allow visibility during the test. By contrast, hydrogen gas fires have significant assets. Firstly, hydrogen gas fire is a realistic scenario when assessing safety of these pressure vessels, as it is a combustible which may always be found near hydrogen storage. Secondly, it is important to note that gas fires are not excessively complex to calibrate, whereas standard pool bonfires involve repeatability issues due to ventilation effects, soot deposition and the high impact of the vessel size on the flame.

In order to increase the amount of energy that can be transmitted to the cylinder during gas fires, and improve the homogeneity of the thermal aggression around it, a confinement is placed above the steel cylinder. The material used to make this confinement is standard aerated concrete. Since the tests can be done with cylinders of various dimensions ( $19 \mathrm{~L} \& 36 \mathrm{~L}$ were used), the geometrical definition of the confinement is located relative to the external walls of the cylinder. This approach allows complete definition of the confinement, regardless of the size of the tested cylinder. A picture of the experimental setup is displayed in Fig. 1.

The cylinder is exposed to fire by the means of four injectors. They are symmetrically located under the cylinder as presented in Fig. 1. This position guarantees a satisfactory engulfment of the cylinder. On each injector, a calibrated flow rate of hydrogen and oxygen mixture can be controlled. The different elements implemented are presented in Fig. 2. The red parts are the elements where the injection of oxygen is performed on each injector. The hydrogen gas fire tests are carried out with $1.5 \mathrm{~g} / \mathrm{s}$ hydrogen and $0.5 \mathrm{~g} / \mathrm{s}$ oxygen flow rates per injector.

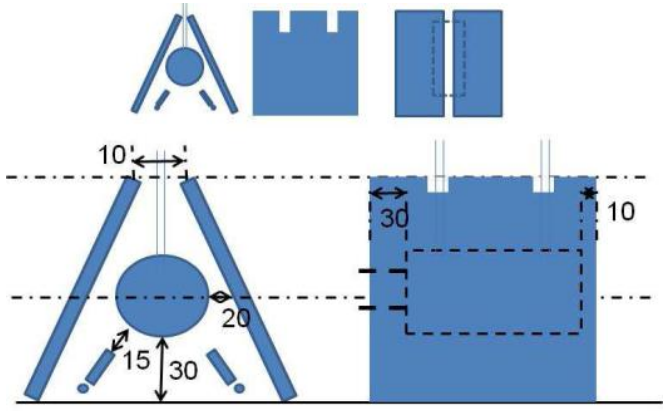

(a)

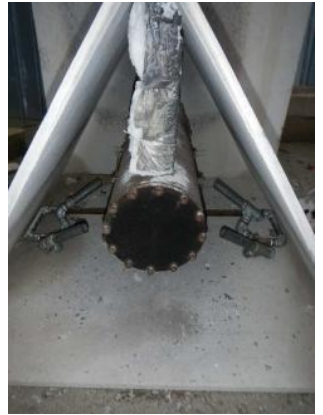

(b)

Figure 1. (a) Definition of the confinement (in $\mathrm{cm}$ ) (b) Steel cylinder with confinement and gas injectors 


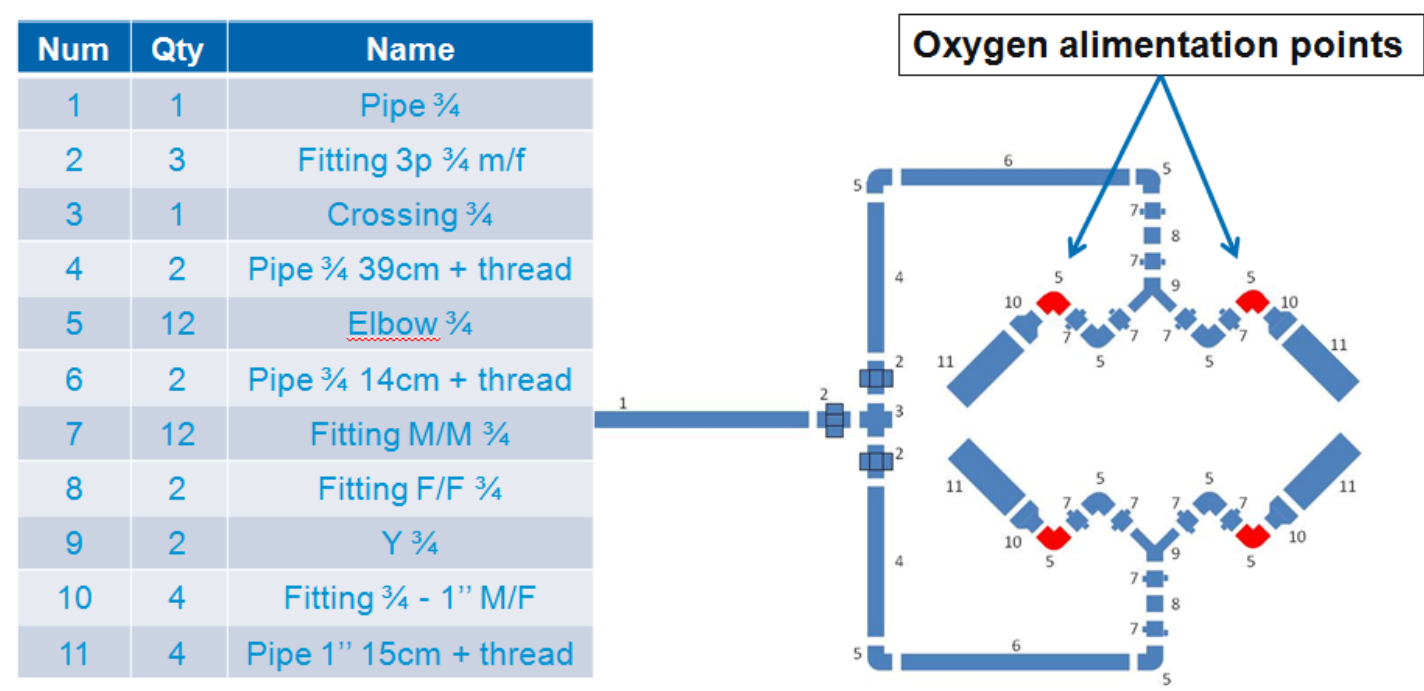

Figure 2. Definition of gas injection circuit

\subsection{Calibration of thermal aggression}

Preliminary tests were performed using a steel cylinder in order to calibrate the heat load measurement method and study the reproducibility of the fire. Thanks to the use of metallic vessels in this preliminary study, there are no issues related to thermal decomposition of the specimen and the thermal properties are well known. The external dimensions of the steel cylinder are the same as those of the $36 \mathrm{~L}$ composite cylinders provided by Hexagon. The sealing of the cylinders is ensured by copper seals, to enable pressure measurements. The weight of the metallic cylinder is about $196 \mathrm{~kg}$. In addition to the pressure measurement, the evolution of temperature is recorded by 24 thermocouples marked by red points in Fig. 3:

- 8 on the internal face of the cylinder,

- 8 on the external face of the cylinder,

- 8 in the flame region.

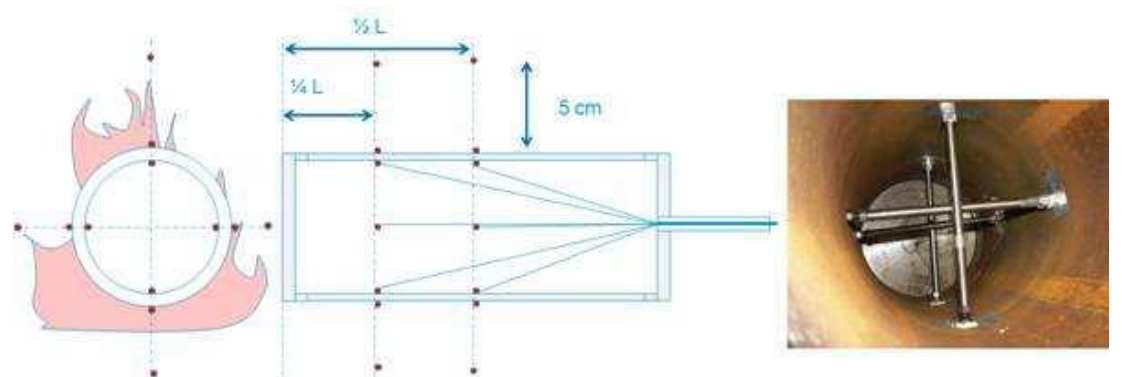

Figure 3. Thermocouples placed inside and around the steel cylinder used for fire calibration

The evolution of the temperature inside the vessel allows determining the net heat flux absorbed by the mock-up, which behaves like a calorimeter. By differentiating the thermal energy stored by the gas $E_{g}$, which can be calculated thanks to the measured temperature of the gas $T_{g}$, the mass of gas $m_{g}$, and its specific heat capacity $C_{p_{g}}$, it is possible to calculate the heat flux $\phi_{S_{i} \rightarrow g}$ transmitted by the internal wall surface $S_{i}$ :

$\phi_{S_{i} \rightarrow g} \times S_{i}=\frac{d\left(E_{g}\right)}{d t}$

with

$E_{g}=m_{g} \times C_{p_{g}} \times \Delta T_{g}$ 
It is then possible to estimate the average temperature $T_{S_{i}}$ of the internal wall of the cylinder, provided the areal transfer coefficient $h$ does not vary appreciably during the test. This coefficient can be estimated at about $4.4 \mathrm{~kW} / \mathrm{m}^{2} / \mathrm{K}$.

$\phi_{S_{i} \rightarrow g}=h \times\left(T_{S_{i}}-T_{g}\right)$

The thermal gradient in the thickness of the vessel wall is calculated thanks to the heat flux $\phi$ absorbed by the cylinder, its thermal conductivity $\lambda\left(32 \mathrm{~W} / \mathrm{m} / \mathrm{K}\right.$ at $\left.1000^{\circ} \mathrm{C}\right)$ and its thickness $e$ :

$\phi=\frac{\lambda}{e} \times\left(T_{S_{e}}-T_{S_{i}}\right)$

Even if the cylinder is assumed to absorb the totality of the heat flux of the gas fire, the thermal gradient in the thickness of the wall remains at a low value of $70^{\circ} \mathrm{C}$ compared to the evolution of the internal wall temperature, which is about $650^{\circ} \mathrm{C}$. It is then acceptable to consider that the temperature is constant in the thickness of the cylinder wall, and is equal to the internal wall surface temperature. Thanks to this assumption, the net heat flux $\phi_{c y l}$ absorbed by the vessel can then be calculated thanks to the evolution of the internal wall surface temperature $T_{S_{i}}$, the cylinder mass $m_{c y l}$, its external surface $S_{e}$ and its specific heat capacity $C_{p_{\text {steel }}}$.

$\phi_{c y l} \times S_{\text {ext }}=m_{c y l} \times C_{p_{\text {steel }}} \times \frac{d\left(T_{s_{i}}\right)}{d t}$

The evolution of the net heat flux received by the cylinder is plotted in Fig. 4. The value of this flux fluctuates over test time around a mean level. An average value of $90 \mathrm{~kW} / \mathrm{m}^{2}$ can be retained, considering that after $400 \mathrm{~s}$ the temperature of the cylinder exceeds $400{ }^{\circ} \mathrm{C}$ and increases the radiative heat flux emitted by the external surface.

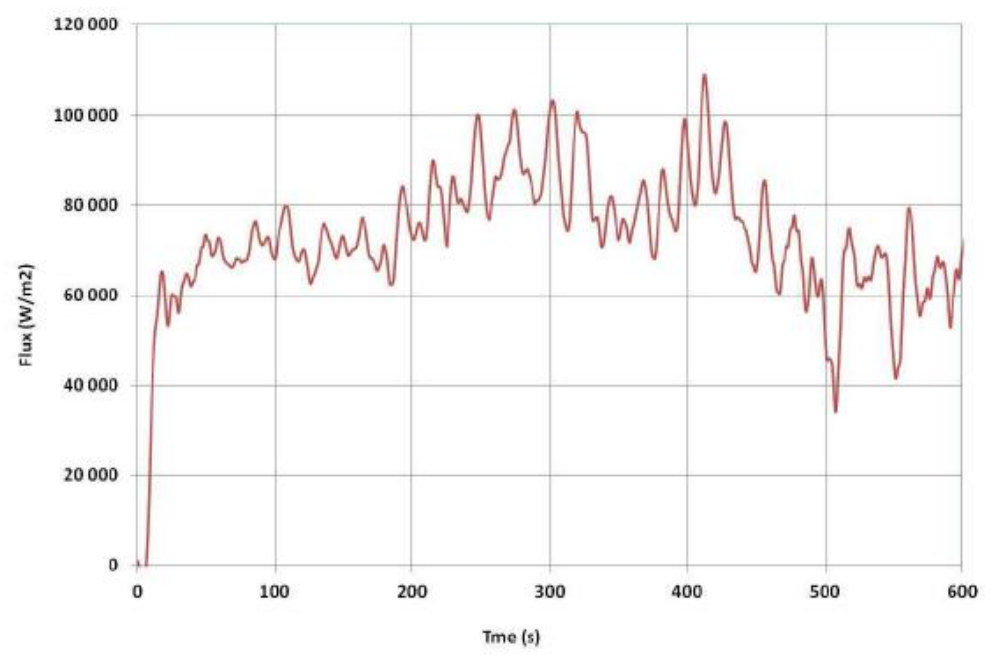

Figure 4. Net heat flux absorbed by the cylinder

Fig. 5 displays the evolution of the external temperatures recorded by the external thermocouples at 5 $\mathrm{cm}$ of the vessel. It can be observed that the temperature fluctuates between $800^{\circ} \mathrm{C}$ and $1000^{\circ} \mathrm{C}$, with a dispersion of very good quality compared to what was measured during bonfire tests with a heptane pool [2]. 


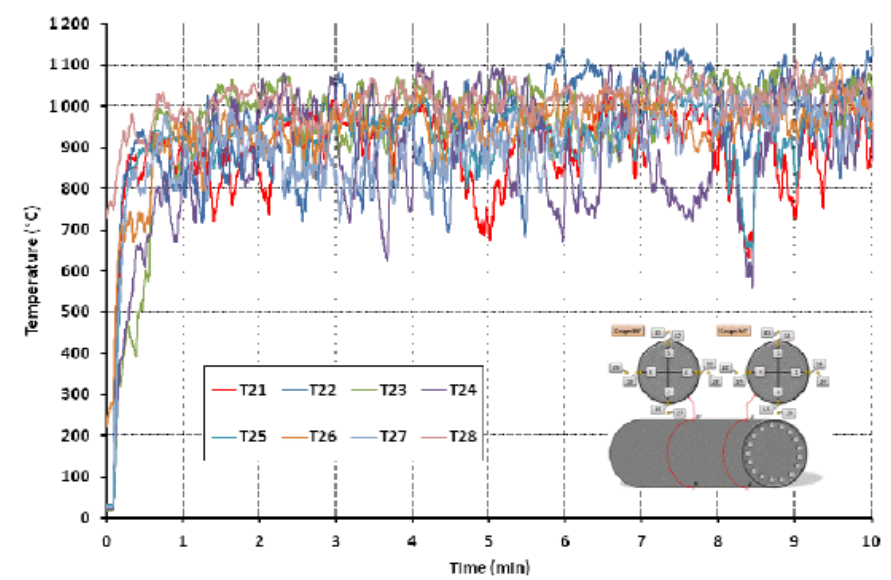

Figure 5. Temperatures recorded at $5 \mathrm{~cm}$ outside of the cylinder

\subsection{RESULTS AND RECOMMENDATIONS}

\subsection{Influence of filling media}

It is expected that replacing hydrogen by helium or nitrogen does not strongly change the behaviour of the vessel but relaxes many safety concerns and simplifies the interpretation of the internal pressure evolution (since helium or nitrogen have a behavior closer to a perfect gas). To check this assumption, the influence of the filling media was studied in a first series of tests.

Six tests were performed with $19 \mathrm{~L}$ vessels at two different inner pressures: 700 bar and 467 bar. For each pressure, three gases were used: hydrogen, helium, nitrogen. As hydrogen was used, bags of sand, concrete walls and a metallic protection were put around the cylinder (Fig. 6) to avoid dangerous projectiles due to the fireball and overpressure that will be generated after burst.
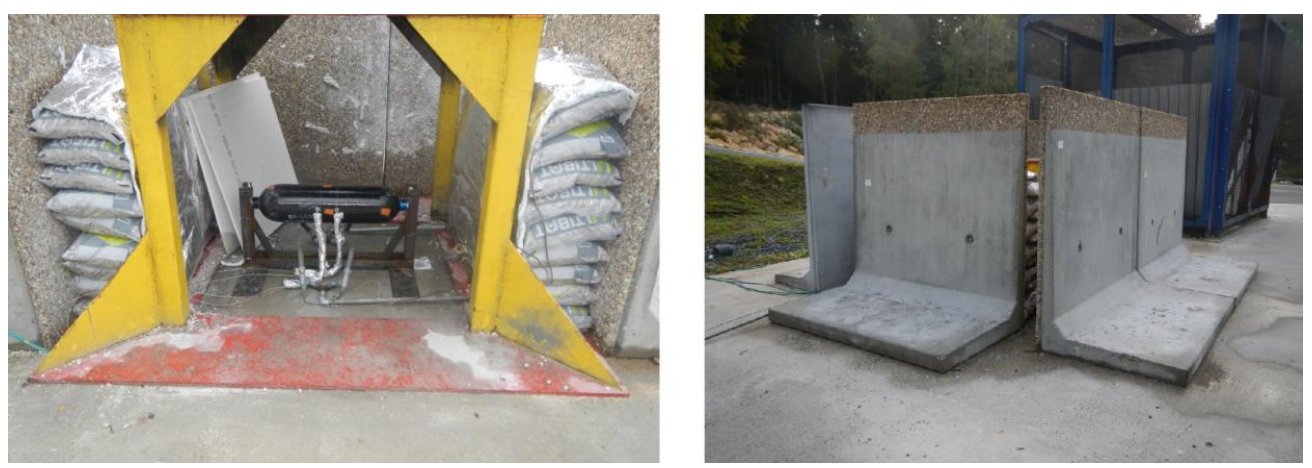

Figure 6. Outdoor experimental setup for hydrogen use (confinement not yet in place in left picture)

The most important results in this phase are the evolution of the inner pressure and the time to burst. The results obtained are presented in Fig. 7 (a) for a 700 bar initial pressure, and Fig. 7 (b) for a 467 bar initial pressure. It appears that there is not an obvious law that governs the behaviour of the cylinders when the initial pressure varies. At 700 bar, the earliest burst occurs with hydrogen, and the latest with nitrogen, with a 15 bar (2\%) and $20 \mathrm{~s}(12 \%)$ relative difference. At 467 bar, nitrogen and hydrogen results are similar, while the test with helium proceeds to burst $35 \mathrm{~s}$ later (20\%), and $15 \mathrm{bar}$ higher (3\%). These facts suggest that the filling media does not have a significant influence on the behaviour of the cylinder, in comparison with the impact of the variability of cylinder strength due to normal uncertainties linked with their fabrication process.

As a result, the subsequent tests were performed with nitrogen, which presents the advantage of being non flammable, thus decreasing the costs and increasing the safety of the experimental campaigns. 


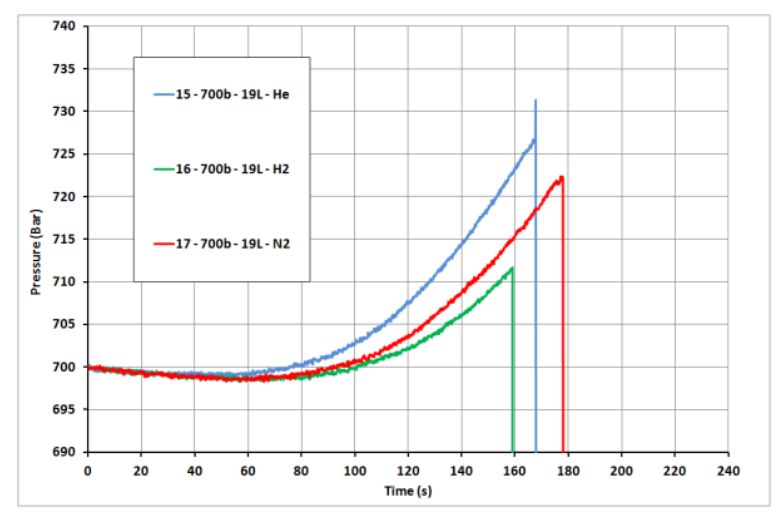

(a)

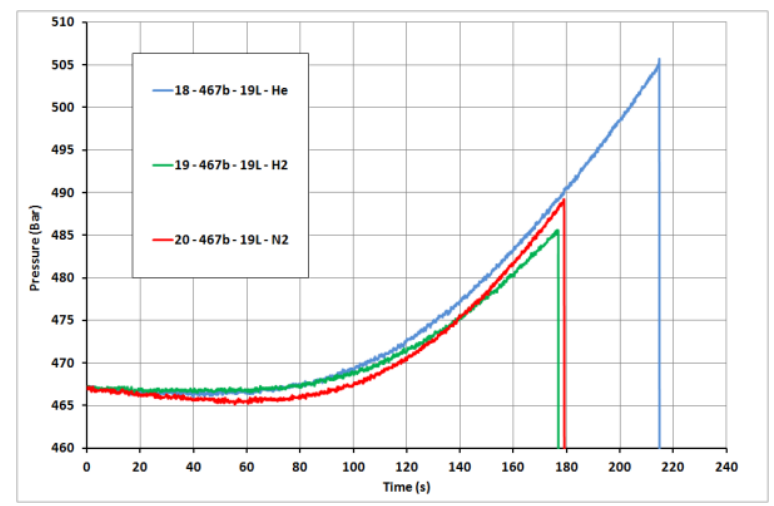

(b)

Figure 7. Evolution of internal pressure for the tests with $\mathrm{He}, \mathrm{N}_{2}, \mathrm{H}_{2}$ at (a) 700 bar (b) 467 bar

\subsection{Tests with different inner pressures}

The tests presented in the following part were performed on $36 \mathrm{~L}$ vessels. According to the previous conclusions, they were carried out using nitrogen gas. The test with initial pressure 700 bar was performed twice on different vessels to assess the reproducibility of the fire aggression. The results are presented in Fig. 8, and it can be seen that both the temperature increase through the composite thickness and the inner pressure increase are very close from one test to the other. The times to burst are $238 \mathrm{~s}$ and $241 \mathrm{~s}$, with pressure increases of around 15 bar.

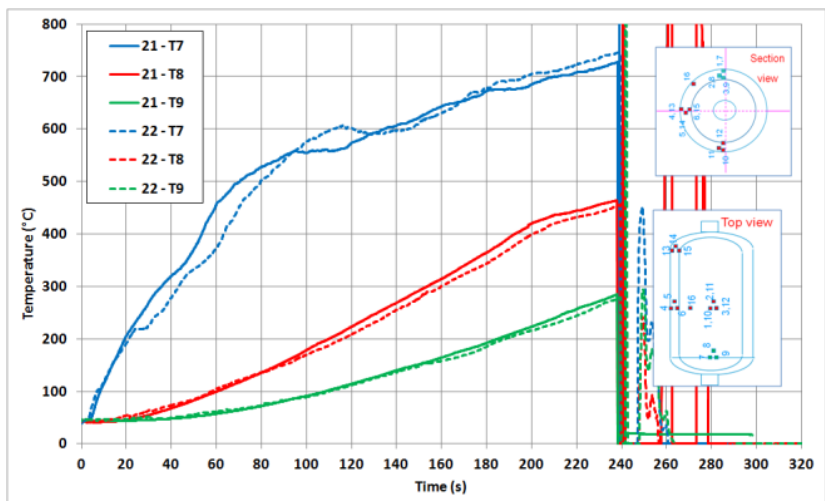

(a)

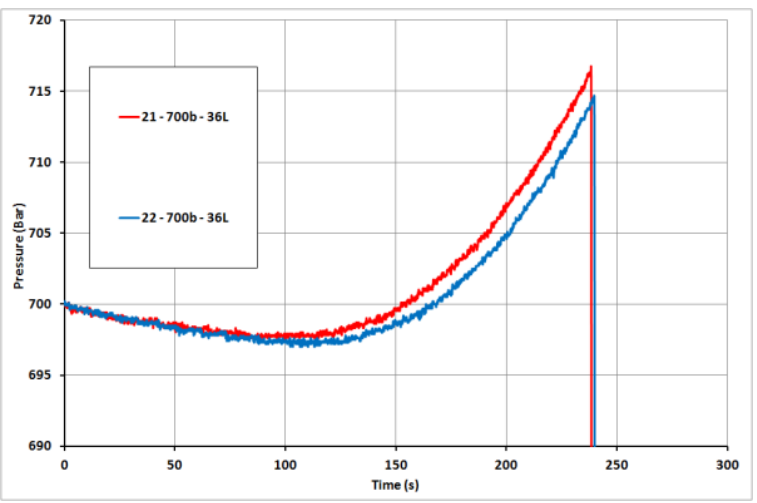

(b)

Figure 8. The evolution of (a) temperature through the composite thickness and (b) inner gas pressure during both of the 700 bar fire tests show a very good reproducibility

During the first $100 \mathrm{~s}$, it appears that internal pressure slightly decreases (by $2.5 \mathrm{bar}$ ), and then increases until burst. This phenomenon can be explained by the fact that vessels were filled just before the test, and stabilization of pressure and temperature was not fully achieved. These curves confirm a well known result regarding the failure mode of composite cylinders: burst does not occur because of the pressure increase, but because the cylinder loses its mechanical properties.

Three other tests were carried out on $36 \mathrm{~L}$ vessels with different initial internal pressure: $100 \mathrm{bar}$, 250 bar and 525 bar. Results are presented on Fig. 9 - for convenience, only one of the 700 bar tests is represented - and the failure times and modes are reported in Table 1. No burst was observed during tests at lower pressures, but break of slopes after 400 and $490 \mathrm{~s}$ respectively indicate the moment when the body of the cylinder starts to leak sufficiently to observe a pressure decrease. This behavior of type IV cylinders has also been reported on completely different cylinders [2] and is attributed to the melting of the polymeric liner.

Table 1. Summary of fire tests results for different initial pressures. 


\begin{tabular}{|c|c|c|c|}
\hline $\begin{array}{c}\text { Initial nitrogen } \\
\text { pressure (bar) }\end{array}$ & Failure mode & $\begin{array}{c}\text { Time to failure } \\
\text { (s) }\end{array}$ & $\begin{array}{c}\text { Pressure } \\
\text { increase }\end{array}$ \\
\hline 700 & Burst & 238 & 15 bar (2\%) \\
\hline 525 & Burst & 311 & 40 bar $(8 \%)$ \\
\hline 250 & Leak & 400 & 55 bar $(22 \%)$ \\
\hline 100 & Leak & 490 & 35 bar (35\%) \\
\hline
\end{tabular}

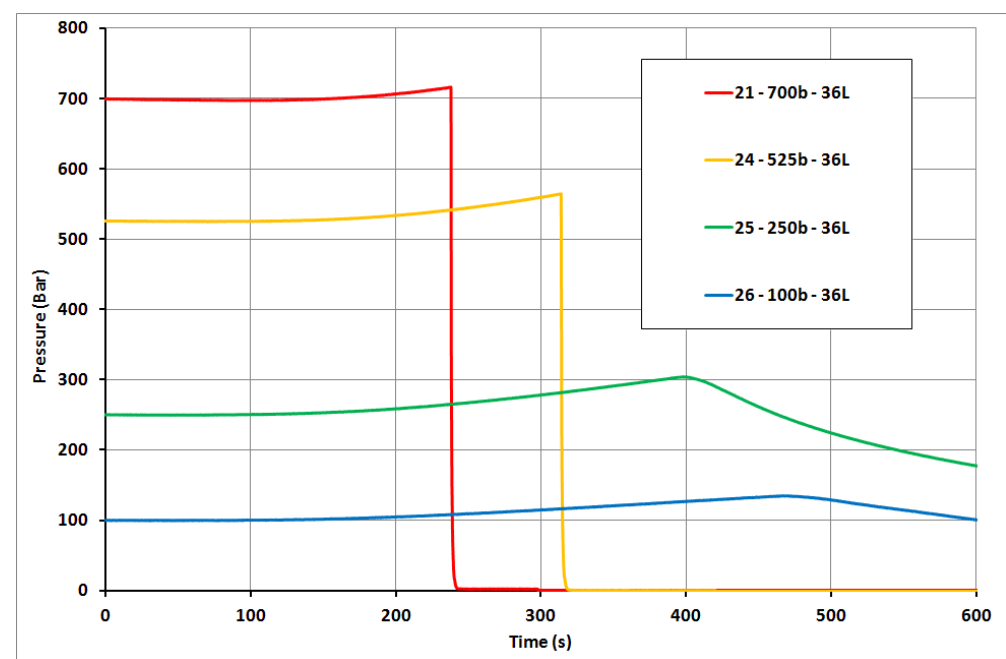

Figure 9. Evolution of inner gas pressure during the four bonfire tests with different initial pressures

\subsection{Recommendations to Regulations, Codes and Standards}

The results presented above are very valuable information for determining a fire safety strategy. For a given application using composite cylinders, if burst is not an acceptable option - which is most often the case - the performance of the bare cylinder can be used in the design of thermal shields and calculation of a depressurisation strategy, to ensure the cylinder is kept in a pressure vs. time zone in which no burst occurs. As an example, the safe pressure zone provided by the tests results of Fig. 9 is displayed in Fig. 10 - an arbitrary safety margin is taken on the time to burst for the example, but the correct value for this margin should be further discussed.

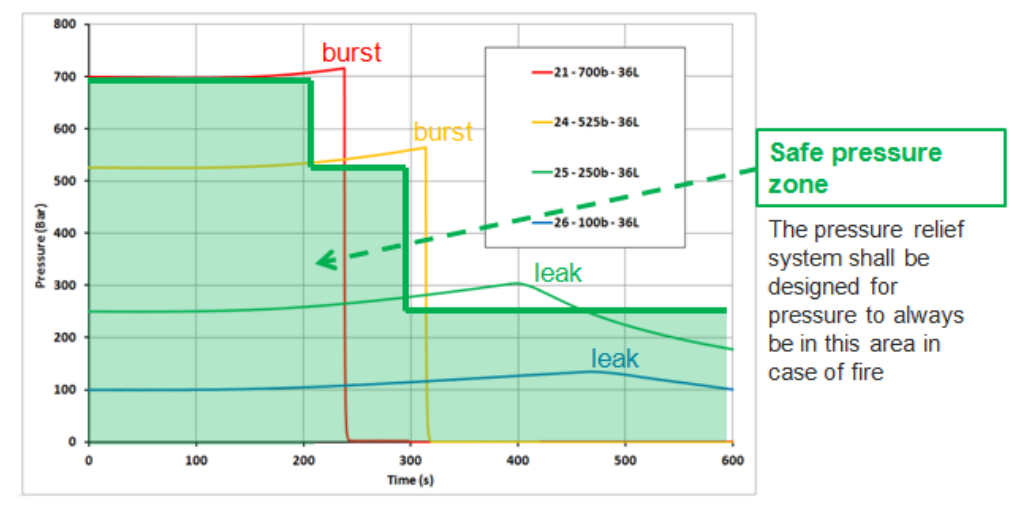

Figure 10. Safe pressure zone determined from the four previous fire tests

It was then recommended by the FireComp project consortium $[15,16,17]$ to separate:

A) on one side, the fire performance of the cylinder itself, exposed to a significant heat flux such as performed with the setup presented above

B) on the other side, the assessment of the safety of the complete structure (car, trailer, stationary storage,...) 
The goal of test A) is to provide the cylinder user with the most reliable information of what the cylinder can endure. As illustrated above, it can be achieved with fire tests at different initial pressures; but this presents the drawback of a very high cost due to multiple expensive tests. An alternative can be considered using only one cylinder and a controlled emptying. Within FireComp, partners Samtech and CNRS developed models, with thermal properties from University of Edinburgh tests, which proved able to accurately reproduce the time to failure and to accurately capture the transition between burst and leak modes, if the materials, geometry and stacking sequence of the cylinder are known.

Such a modelling approach can be used by the cylinder manufacturer to anticipate a pressure relief curve, and choose a combination of (time to activation; depressurisation rate) to be tested with a cylinder. Unlike when using a TPRD, the pressure relief is manually triggered, to provide a safe pressure zone such as displayed in Fig. 11. This method presents the advantage of requiring only one fire test.

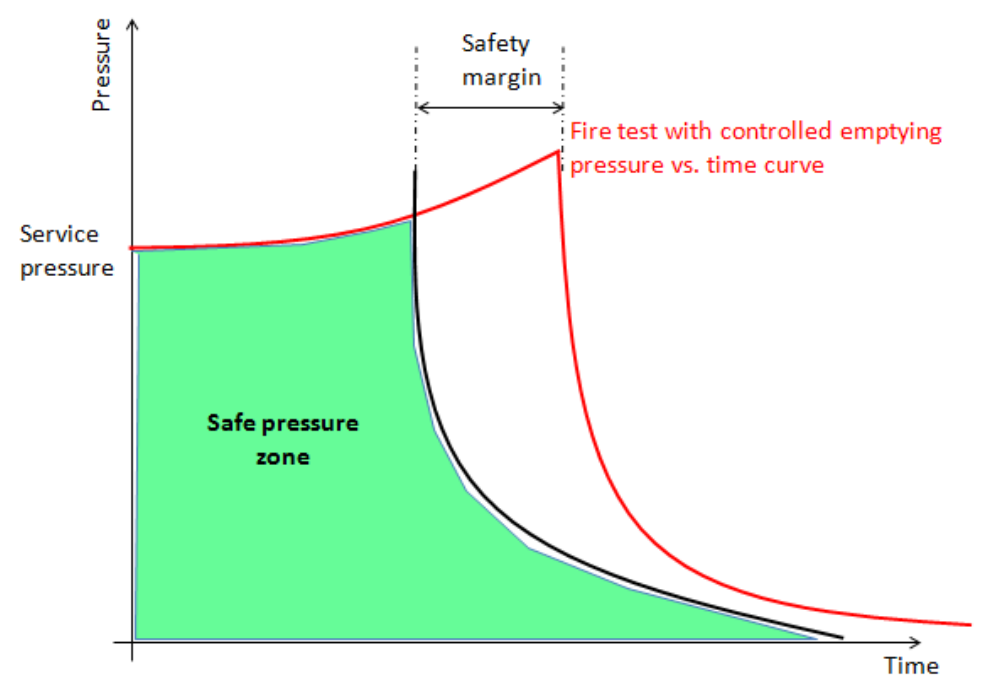

Figure 11. Method for obtaining a safe pressure zone with only one test. Experimental pressure curve in red, safe pressure zone in green - an arbitrary safety margin on time is displayed as an example

Then, the purpose of part B) is for the integrator or end-user of the cylinder to choose and test their fire safety elements according to the risk analysis of the application considered. The advantages of this method are that:

- only one full scale fire test on a composite vessel is required; it provides more information than actually required by the norms; and need not be repeated in case of changes to the pressure relief system,

- the fire safety elements (shields, pressure relief devices...) can be adapted according to the real risks,

- the functions of the pressure relief system (detection of the fire and proper opening) can be tested separately.

\subsection{APPLICATION TO THE FIRE SAFETY OF A MULTI-ELEMENT GAS CONTAINER}

This section gives an example of how the previous results can be used to define a fire safety strategy for a specific application: a bundle using composite cylinders for delivery of high pressure hydrogen, displayed in Fig. 12. Four composite cylinders of volumes approx. $150 \mathrm{~L}$ and service pressure 700 bar are connected together, transported on the road and delivered as stationary storage for a power generation unit. 


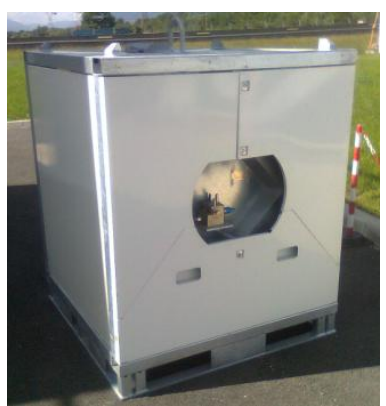

(a)

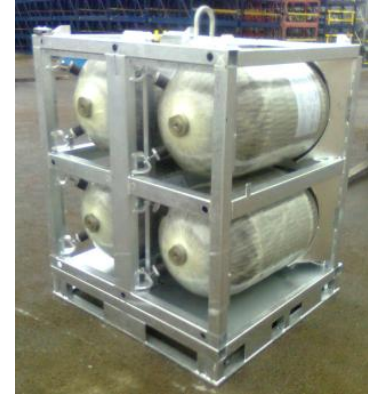

(b)

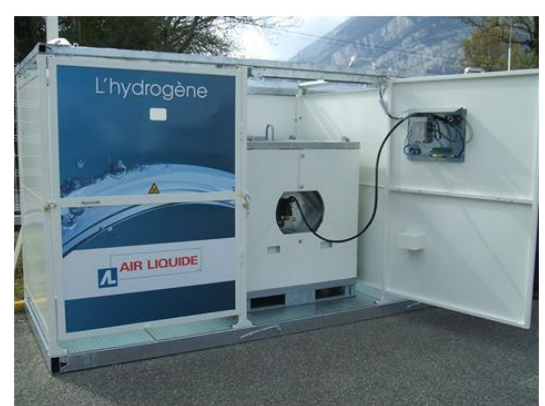

(c)

Figure 12. (a) Picture of the hydrogen bundle, (b) without the external metallic frame, (c) in use

In case of fire, the effects of a burst of one of the cylinders have been assessed. Considering the speed of the burst event, it can be assumed that the four cylinders will burst separately and that the safety distances to be considered are the same as for a single cylinder. The safety distance associated to a 50 mbar overpressure (French threshold for irreversible effects) was calculated using dedicated engineering tools [18] to be $34 \mathrm{~m}$, which was not acceptable for this application. A pressure relief strategy using a TPRD was decided upon.

The performance of the cylinder alone was assessed using the methodology presented above. The results obtained are gathered in Fig. 13, from reference [2]. It was decided to install one TPRD for the complete bundle, which should vent all four cylinders simultaneously in case of fire. A metallic frame was used around the bundle for two fire-related reasons: 1) to protect the cylinders from localised jet fires and ensure heat would be transferred to the TPRD, and 2) to delay the fire aggression on the cylinders and increase the time to burst, allowing more time for the pressure relief process, hence limiting the flame length to acceptable levels in case of ignited hydrogen release. It also protects the cylinders from mechanical impacts. A fire test on a cylinder integrated in a bundle was performed and the time to burst at 700 bar was delayed to 13 minutes.

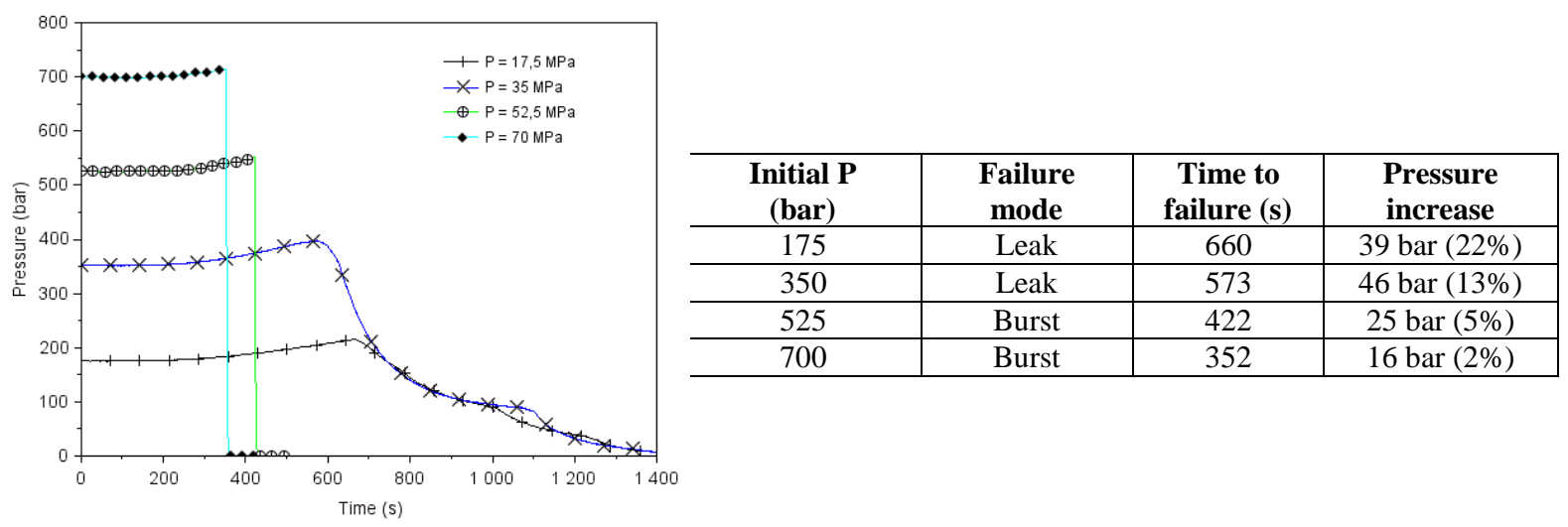

Figure 13. Results from fire tests

The required pressure relief rate was then used to calculate the diameter of the calibrated orifice at the exhaust of the TPRD. The capacity for the TPRD to open when exposed to heat was tested separately, to ensure satisfactory reaction times. The resulting numerical simulation of the pressure relief of the complete bundle is displayed in Fig. 14, which summarises the final safety strategy. 


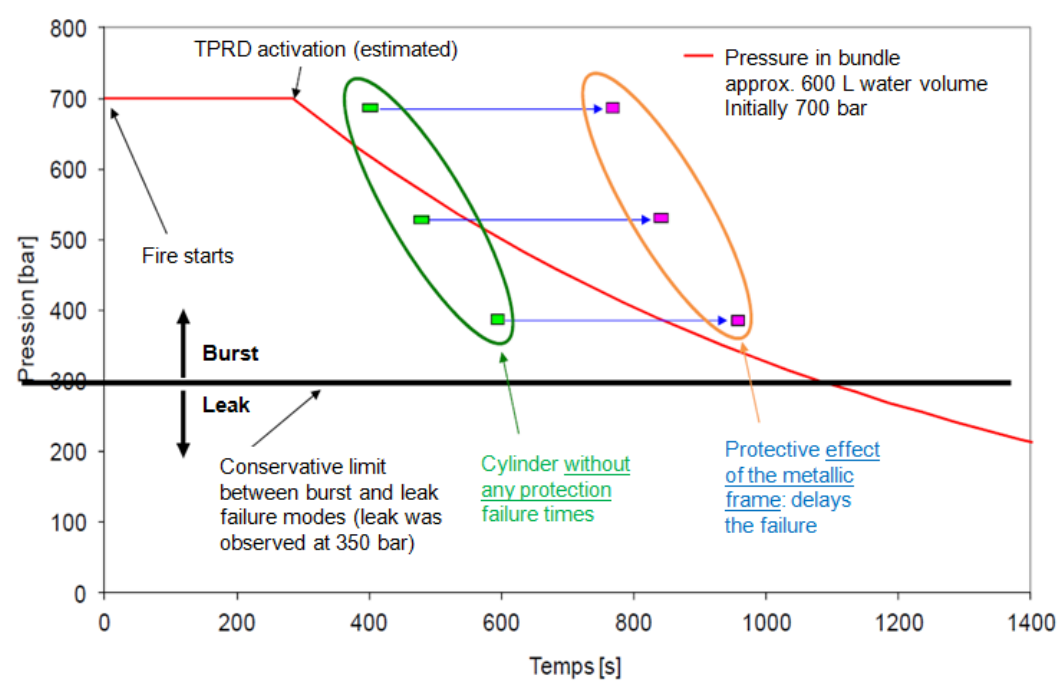

Figure 14. Summary of the fire safety strategy for the bundle. The performance of the unprotected cylinder is known, a metallic frame facilitates delaying the failure, and the flow rate is calibrated so that pressure always remains within the safe envelope.

\subsection{CONCLUSIONS}

A large programme of full-scale fire tests on type IV composite cylinders was performed within the project FireComp. An experimental setup using hydrogen gas burners as a fire source was specified, and proved able to reach an equivalent level of heat stress as with conventional bonfire test systems. A method for calibrating the fire was proposed, which led to fire tests of very good reproducibility. Moreover, the setup can easily be adapted to different sizes or shapes of cylinders.

Results of fire tests carried out on pressurised cylinders without any protection allowed exploration of their behaviour. It was confirmed that below a certain pressure level, in an engulfing fire, the failure mode switches from burst to leak through the body. This is due to a competition between on the one side, the degradation of the composite material, which leads to a burst when the pressure can no longer be contained; and on the other side, the heat transfer to the liner, which leads it to melt and creates a pathway for the gas to exit through the cylinder. A potential path of research could be to design a pressure vessel for which the only failure mode in fire is a leak, by increasing the thermal conductivity while limiting the loss of strength of the composite layup. However, so far the leak through the cylinder body is not fully mastered and cannot be guaranteed in all fire conditions, so the use of a pressure relief system is mandatory when burst must be avoided.

In order to design a pressure relief system well adapted to how the cylinder is used, it was proposed in FireComp to separate the testing of the cylinder performance for the testing of the system performance. In the first step, independently of the application, an unprotected cylinder is exposed to fire until failure, or until a controlled emptying, which provides a safe pressure vs. time chart. In the second step, the capacity of the complete system (e.g. stationary bundle or vehicle storage system) to actually detect fire and safely release the pressure is assessed. An advantage of this method is to provide more information for the choice of a safety strategy adapted to the specificities of the application; meanwhile reducing the number of fire tests required on composite cylinders, as no new qualification of the cylinder is needed if a safety element is changed. A limitation is that the second step, i.e. assessment of the safety at system level, is harder to standardise; but this may be inevitable considering the wide range of possible applications for the same cylinder. 


\subsection{ACKNOWLEDGMENTS}

The research leading to these results has received funding from the European Union's Seventh Framework Program (FP7/2007-2013) for the Fuel Cells and Hydrogen Joint Technology Initiative under Grant Agreement No.325329.

Parts of the work presented received financial support from OSEO H2E project (2009-2016).

\subsection{REFERENCES}

1. Barthelemy, H., Weber, M., Barbier, F., Hydrogen storage: Recent improvements and industrial perspectives, International Journal of Hydrogen Energy (2016), http://dx.doi.org/10.1016/j.ijhydene.2016.03.178

2. Bustamante-Valencia, L., Blanc-Vannet, P., Domergue, D., Heudier, L., Jamois, D., Thermal History Resulting in the Failure of Lightweight Fully-Wrapped Composite Pressure Vessel for Hydrogen in a Fire Experimental Facility, Fire Technology, August 2015, pp 1-22.

3. Saw, J.L., Flauw, Y., Demeestere, M., Naudet, V., Blanc-Vannet, P., Breuer, P., Hollifield, K., Wilday, J., The EU FireComp Project and Risk Assessment of Hydrogen Composite Storage Applications using Bow-tie Analysis, Hazards 26, Edinburgh, UK, 24-26th May 2016

4. Regulation (EC) No 79/2009 of the European Parliament and of the Council - on type-approval of hydrogen-powered motor vehicles

5. NF EN 12245+A1 Transportable gas cylinders - Fully wrapped composite cylinders

6. FireComp website: www.firecomp.info

7. Breuer, P., Fuster, B., Kiener, E., Hawksworth, S., Halm, D., Boulet, P., van Eekelen, T., Fouillen, F., Welch, S., Modelling the thermo-mechanical behavior of high pressure composite materials vessels when exposed to fire conditions, 21st World Hydrogen Energy Conference, Zaragoza, Spain, 13th-16th June 2016

8. Hidalgo, J.P., Pironi, P., Hadden, R.M. and Welch, S., A framework for evaluating the thermal behaviour of carbon fibre composite materials, in Proceedings of the 2nd IAFSS European Symposium of Fire Safety Science. pp. 195-200, 2nd European Symposium of Fire Safety Science, Nicosia, Cyprus, 16 June 2015

9. Alemany Mary, V., Berro Ramirez, J.P., Halm, D., Rogaume, T., Ropital, M., Residual strength of wound composite pressure vessels subjected to fire exposure, 16th European Conference on Composite Materials, Sevilla, Spain, 22nd-26th June 2014

10. Benelfellah, A., Halm, D., Quach, T.H.Y, Rogaume, T., Bertheau, D., Residual mechanical properties of a carbon/epoxy wound composite exposed to fire, 22ème Congrès Français de Mécanique, Lyon, France, 24th-28th August 2015

11. Benelfellah, A., Lainé, E., Gueguen, M., Halm, D., Bertheau, D., van Eekelen, T., Germain, F., Simulation of burst of hyperbaric hydrogen tanks in fire conditions, 17th European Conference on Composite Materials, Munich, Germany, 26-30th June 2016

12. Chaineaux, J., Devillers, C., Serre-Combe, P., Sûreté des dispositifs de stockage de l'hydrogène sous haute pression équipant des véhicules routiers, Contrat $\mathrm{n}^{\circ}$ 13461-97-11 F1ED ISP F, 2000

13. Peters, S.T., Composite filament winding, ASM International, 2011

14. Ruban, S., Heudier, L., Jamois, D., Proust, C., Bustamante-Valencia, L., Jallais, S., KremerKnobloch, K., Maugy, C., Villalonga, S., Fire risk on high-pressure full composite cylinders for automotive applications, International Journal of Hydrogen Energy, 37, pp.17630-17638, 2012

15. Blanc-Vannet, P., Heggem, P.S., Recommendations to Regulations, Codes and Standards, FireComp project webinar, Paris, May $23^{\text {rd }} 2016$, available online $w w w$.firecomp.info

16. Heggem, P.S., Behaviour of composite cylinders in fire - Recommendations to Regulation, Codes and Standards bodies provided by the EU project FireComp, Pressurized Hydrogen and Storage Equipment conference, Leuven, Belgium, $16^{\text {th }}-17^{\text {th }}$ May 2016 
17. Heggem, P.S., Industrial perspective on fire safety of composite cylinders in hydrogen applications, Proc. Hydrogen Bridge: Safety of High-Pressure Hydrogen Storage, Hangzhou, China, 2016

18. Houssin-Agbomson, D., Jallais, S., Développement d'outils d'ingénieurs pour l'évaluation du risque hydrogène. Lecture, Lambda Mu Conference, St-Malo, France, $11^{\text {th }}-13^{\text {th }}$ Oct. 2016. 